\title{
Local Breakdown of the Allergen Tolerance in the Nose
}

\author{
Vladimir Klimov ${ }^{1}$ and Andrew Klimov ${ }^{1}$ \\ ${ }^{1}$ Siberian State Medical University
}

August 5, 2020

\begin{abstract}
Allergen tolerance is an active physiological process, which runs opposite to the adaptive immune response. The induction of allergen tolerance involves the multiple regulatory networks of cells and biomolecules. There are $\mathrm{T}$ regulatory cells, tolerogenic dendritic cells, IL10, IL35, TGFb, and immunosuppressive neurotransmitters. of this review is the overview of allergen tolerance mechanisms and its breakdown at the systemic and local levels, particularly concerning such specific organ as the nose. In this review, immune tolerance is initially considered on the whole. Then the review focuses on mechanisms of the physiological induction of allergen tolerance throughout the body, and pathogenesis of allergen tolerance breakdown with particular emphasis on both systemic and autonomous starting-off, taking into account two diverse entities (endotypes) of allergic rhinitis. Recently, two diverse endotypes, classical (conventional) allergic rhinitis and local allergic rhinitis, have been recognized. Although local allergic rhinitis revealed a decade ago, its immunopathogenesis is partially unclear, and a proper therapeutical protocol is not eventually developed. The possible role of neurotransmitter imbalance during the pathogenesis allergen tolerance breakdown is discussed. Accordingly, we proposed the hypothesis of autonomous allergen tolerance breakdown in local allergic rhinitis.
\end{abstract}

\section{Hosted file}

hypothesis of autonomous breakdown.mp3 available at https://authorea.com/users/333140/ articles/459400-local-breakdown-of-the-allergen-tolerance-in-the-nose

\section{Hosted file}

Main Text.doc available at https://authorea.com/users/333140/articles/459400-local-breakdownof-the-allergen-tolerance-in-the-nose 


\section{About $1,000,000$ years}

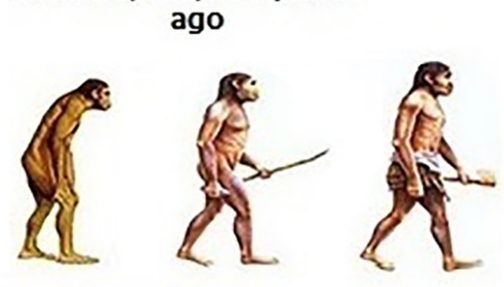

Protective IgE in $\mathbf{1 0 0 \%}$ of human populations

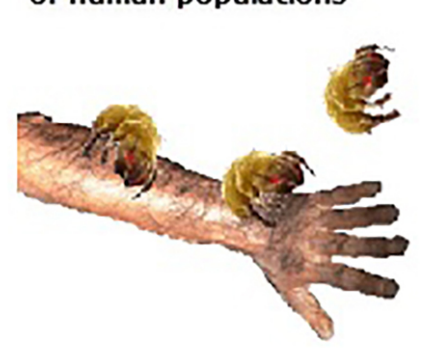

Surface of the skin

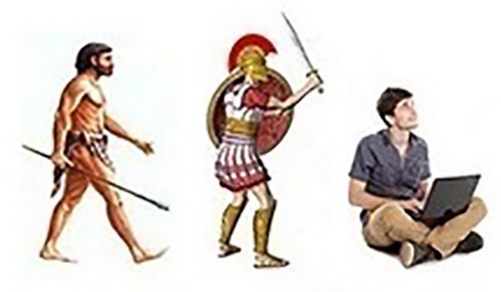

"Allergenic" IgE in 7-10\% of human populations (evolutionary vestige)
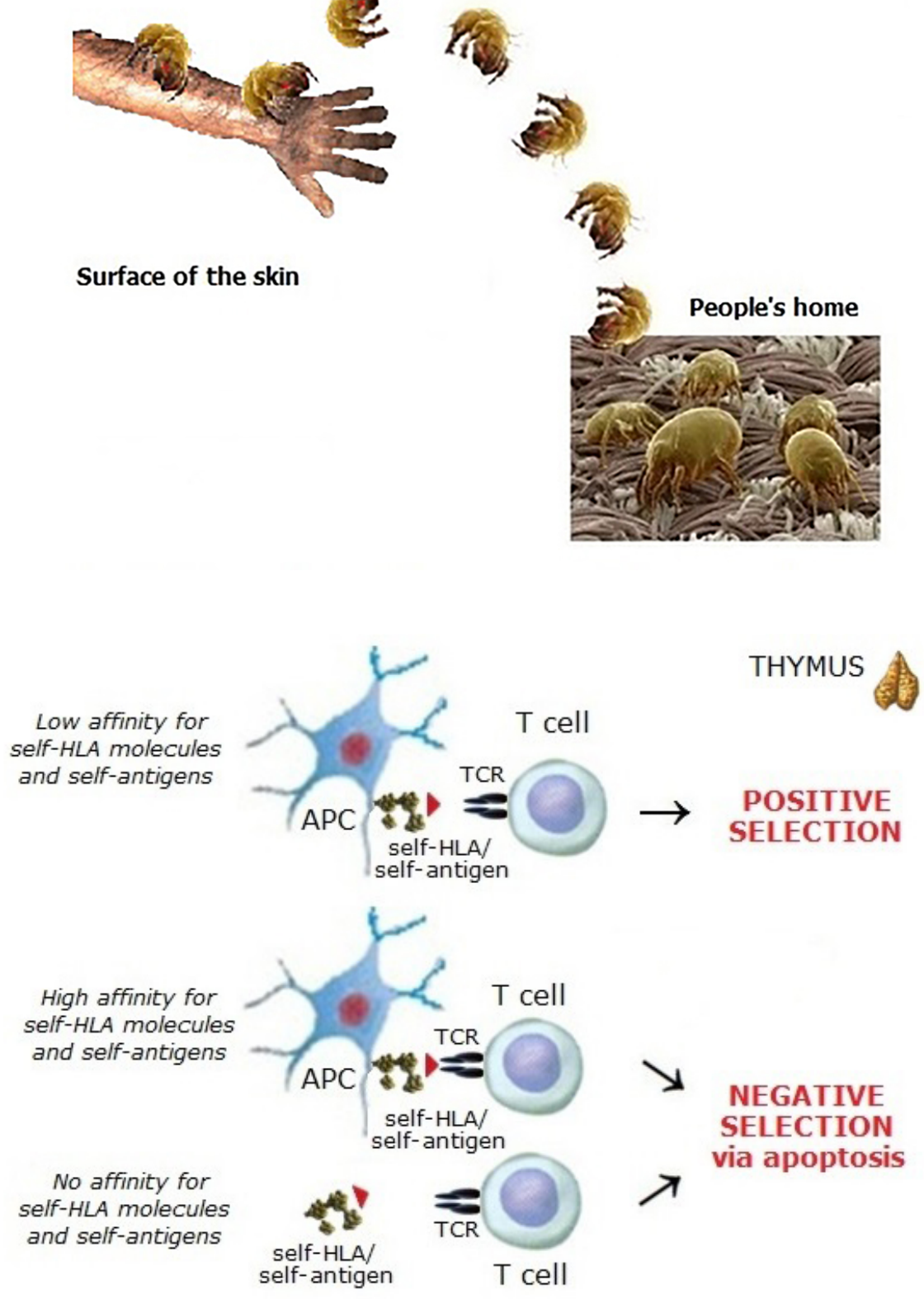

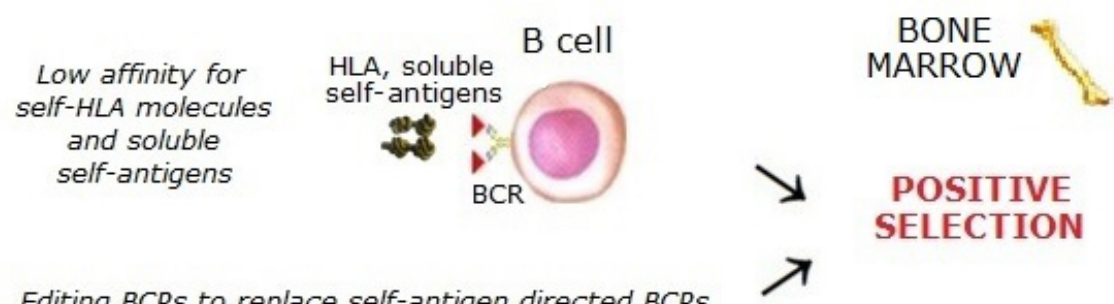

Editing $B C R$ s to replace self-antigen directed $B C R s$ by foreign antigen directed BCRS

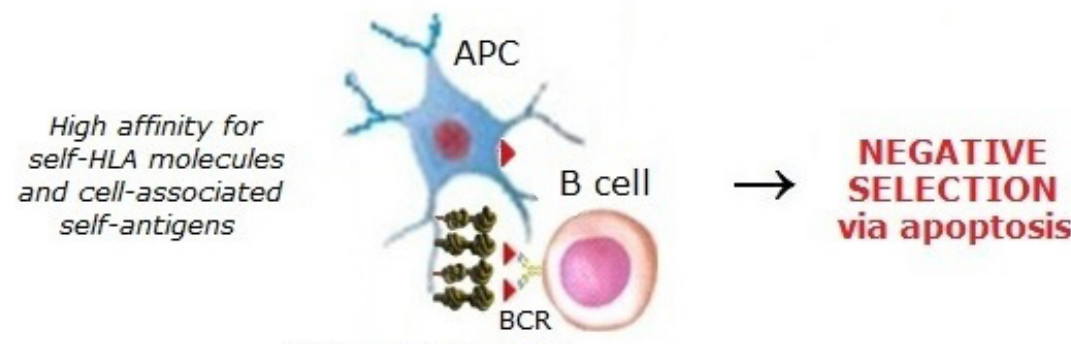

HLA, cell-associated self-antigens

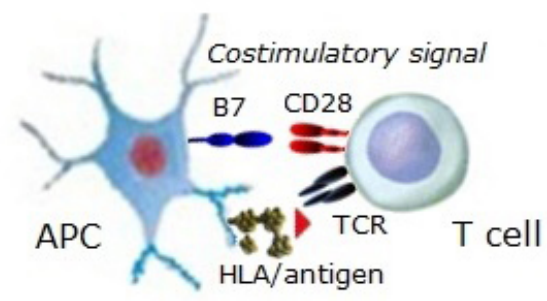

$\rightarrow$ IMMUNE RESPONSE
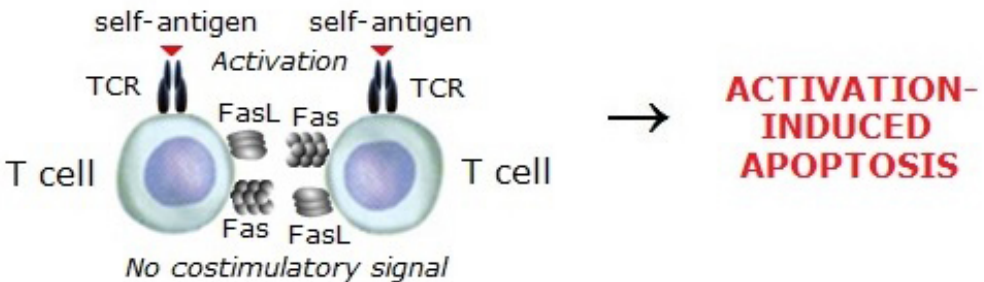

No costimulatory signal 

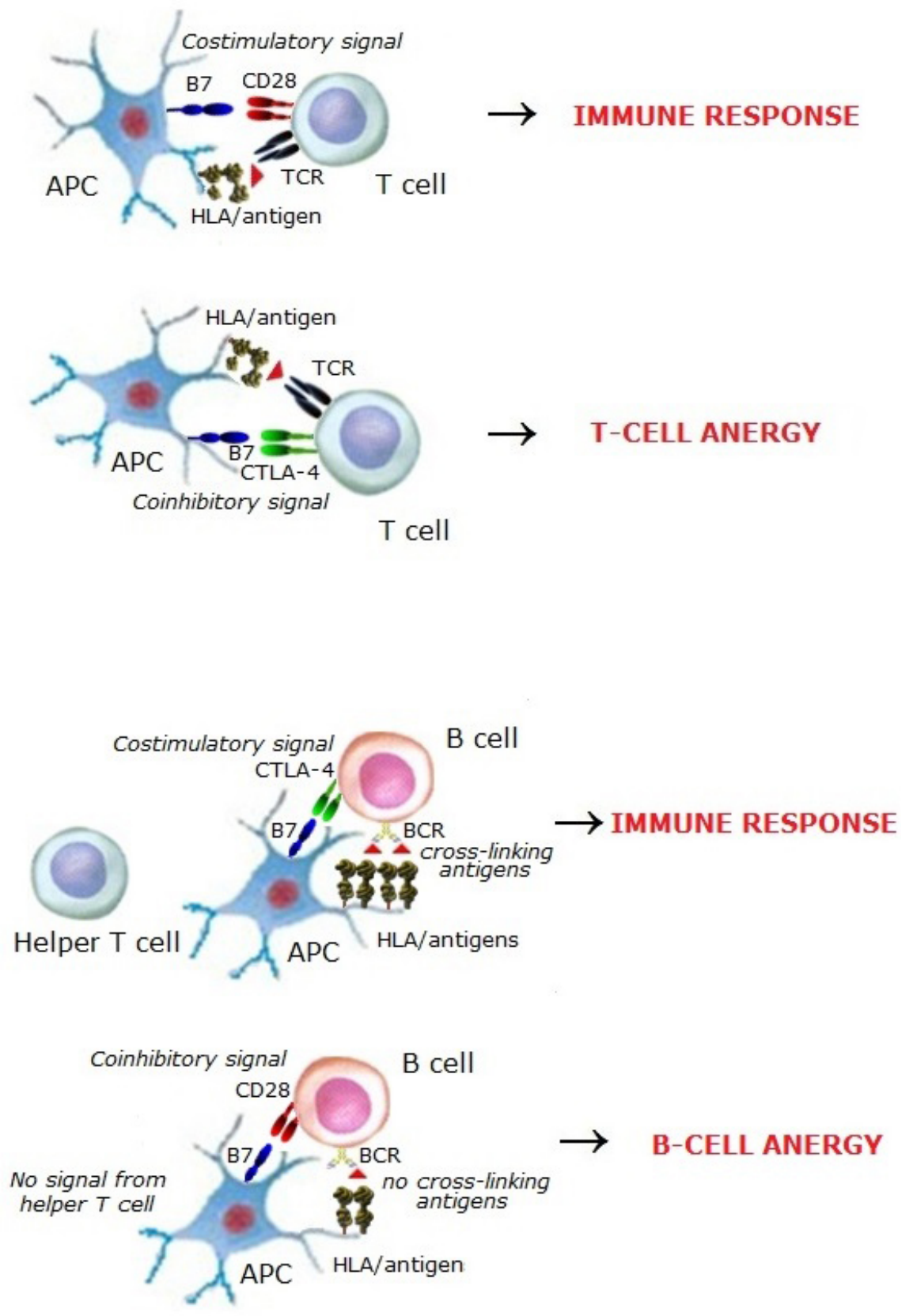

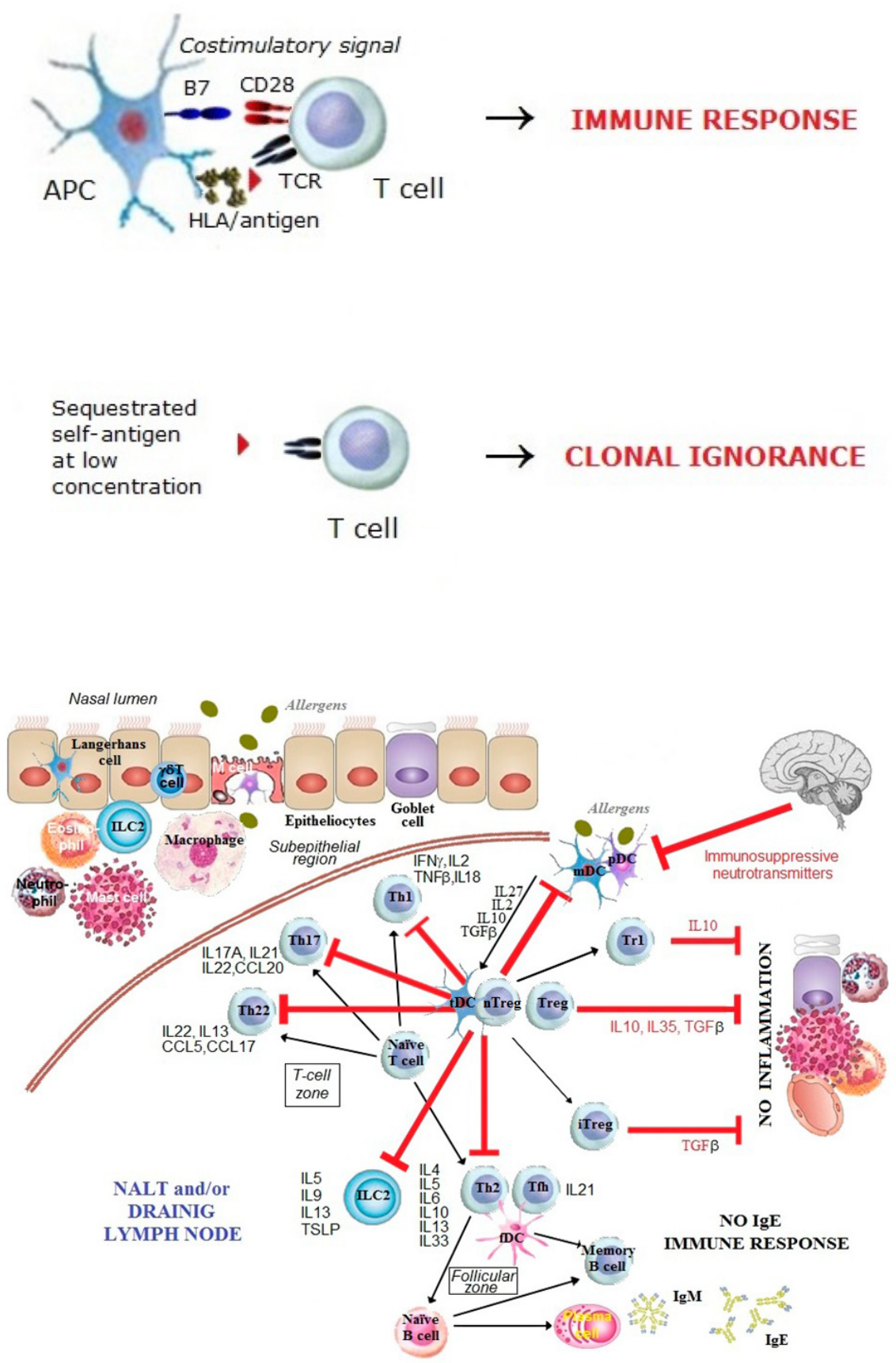